\title{
A Platonic kind-based account of goodness
}

\author{
(July 2020 Pre-refereed version of Philosophia [2021]: 1-21. \\ https://doi.org/ 10.1007/s11406-020-00309-z) \\ By Berman Chan, Purdue University \\ bermanchan77@gmail.com
}

Robert Adams defends a platonic account of goodness, understood as excellence, claiming that there exists a platonic good that all other good things must resemble, identifying the Good with God. Mark Murphy agrees, but argues that this platonic account is in need of Aristotelian supplementation, as resemblance must take into account a thing's kind-membership. While this article will accept something like Murphy's account of goodness (but without claiming the platonic good is God), it will further develop its details and support. Without relying on theistic premises, I show that the metaphysical status of an individual's goodness consists in resemblance with the platonic good. As for the distinct question of what that goodness holds in virtue of, I conclude it holds in virtue of exactly: the thing's own properties, those properties being such as to satisfy its kind-based standards (K-standards), and those K-standards resembling the platonic good. I then develop an account of how K-standards resemble the platonic good: The K-standards resemble it firstly with respect to requiring activities, as the platonic good will be posited to be active, and must resemble it secondly also at the level of what teleology those activities are directed towards. I also motivate the need for a third respect of resemblance, to be developed in future work. The article ends with a discussion of the nature of the platonic good. 
What is it for something to be good, where goodness here is understood as excellence? Call a platonic account one that claims that there exists a platonic good that all other good things must either resemble or instantiate. Robert Adams, in Finite and Infinite Goods (2002), defends such an account of goodness, contending that resemblance with the platonic good (which he identifies with God) is what the goodness of other things consists in. Mark Murphy (2011), however, argues that this platonic account is in need of Aristotelian supplementation, as it is plausible this resemblance must occur within the context of a thing's kind-membership.

This article will offer an account of goodness concerning living beings that are members of kinds, and while it will accept Murphy's account of goodness (but without identifying the platonic good with God), it will further develop the details of such a position with respect to: providing the exact determinants that something's goodness is in virtue of, providing an argument (without presupposing theism) that something's goodness consists in resemblance with the platonic good, and detailing an account of what it is for something to resemble while something else does not resemble the platonic good. I will organize this work by making a distinction between the question of what something's goodness obtains in virtue of, and the question of what that goodness in turn consists in (with regards to its metaphysical status).

I will begin with a brief exposition of Adams' account of the platonic good, which will be important background for my discussion. Next, I will tackle the first question above of what something's goodness obtains in virtue of, explaining why an individual's goodness must hold in virtue of both resemblance to the platonic good and also kind-based considerations. I sharpen this claim later, but I first use this coarse-grained claim that an individual's goodness holds in virtue of these two determinants, in order to tackle the second question, which asks what the metaphysical status of that individual's goodness consists in. I respond with an argument that an individual's goodness consists in its resemblance to the platonic good, rather than consisting in goodness as a member of its kind. Next, I return to provide more precision to the question of what an individual's goodness holds in virtue of, and conclude that it is in virtue of exactly the following determinants: the thing's own properties, those properties being such as to satisfy its kind-based standards (Kstandards), and those K-standards resembling the platonic good. I then develop an account of how $\mathrm{K}$-standards resemble the platonic good: the K-standards resemble it firstly with respect to requiring activities, as the platonic good will be posited to be active, and must resemble it secondly also at the level of what teleology those activities are directed towards. The article ends with a discussion of the nature of the platonic good, including an argument that the latter is an exemplar rather than a property, and that the platonic good is metaphysically necessary.

1. Robert Adams' account of the platonic good

Adams' account of the platonic good is important background for this entire discussion. The goodness that interests Adams is not goodness construed as usefulness or what is good for things (well-being), but rather goodness that is excellence. This is the goodness "of that which is worthy of love or admiration", and unqualifiedly so regardless of time, place, and so forth (Adams 1999: 13). Moral virtues are excellences, but excellence is not exclusively moral. Adams points to beauty as an important example of platonic excellence, alluding to Plato's notion of a transcendent Beauty, found in the Symposium, where Beauty "is the standard of all beauty and all other beautiful things are beautiful by 'participating' (211B) in it." (Adams 13) For Adams, this transcendent Good is the monotheistic God, as it was for Augustine and many others (14). Adams points out that he has 
no interest in defending a theory of universals, but rather a theory of value. In addition, he has no interest in representing the beliefs of the historical Plato per se. However, Adams does take a stand regarding two interpretations that are distinguished in Platonic scholarship about the Forms: One in which they are primarily exemplars, the other in which they are properties or universals. As Adams takes the platonic good to be God, and thus not an abstract object "but a concrete (though not a physical) individual" (14), it is perhaps no surprise that Adams conceives of the platonic good as an exemplar.

As the transcendent Good, the single platonic form of excellence is held to be capable of accounting for all varieties of goodness, a thesis with which Aristotle famously disagrees. As Adams observes, Aristotle claims "that the diversity of things that are noninstrumentally good is too fundamental for their goodness to be accounted for in terms of a single Platonic Form" (Adams 38). For Aristotle, there are as many sorts of goodness as can be predicated in each Aristotelian category. Further, it seems to me that for Aristotle things are too diverse also because individuals belong to different kinds, and so their goodness cannot be explained by a single transcendent Good. But Adams argues that even if there are varieties of excellence, this does not entail that they are not good in virtue of a relation to some one supreme Good: "All other good things are good by virtue of their relation to one supremely good thing, the central relation being a sort of resemblance or imaging." (40) Thus, for Adams this transcendent good is a kind-independent and ultimate standard that all other things are good in virtue of resembling.

But Adams is clear that not every sharing of a property with the platonic good counts as resemblance. "Judgments of resemblance are more holistic than that. Suppose there is a squirrel that has the same number of hairs on its body that I have on mine. We would not ordinarily say that this rodent 'resembles' me in that respect." (32) Instead, he argues that there must be a certain context within which resemblance holds, and so resemblance is holistic. This context, he eventually argues, is the sharing of properties in a way that gives God a reason for loving the thing. So, "being excellent in the way that a finite thing can be consists in resembling God in a way that could serve God as a reason for loving the thing." (36)

Now, Adams readily grants that the meaning of the term 'good' is not identical to resembles God (15). However, he makes use of classic work in the philosophy of language by Hilary Putnam (1975) that distinguishes and clarifies the relationship between questions of nature and questions of meaning, famously utilizing the example of water. As for considerations of meaning, Adams draws from more themes in the Symposium and argues that the semantics of 'good' will include being the object of our admiration, desire, and recognition (Adams 19-20). Not that we always admire or desire good things, or never admire bad things; after all for Adams the nature of the good is not based upon facts of our desires. Though our pursuit (Eros) of the Good can be mistaken, Adams insists that we are not always wrong. " $\mathrm{I}] \mathrm{f}$ we do not place some trust in our own recognition of the good, we will lose our grip on the concept of good [...]” (20). For this reason, Adams argues persuasively that traits like being sadistic or loving cowardice are contrary to the semantics of goodness (46). What about the distinct question of the nature (rather than semantics) of goodness? In response, he lays out the following strategy to account for the relationship between semantics and metaphysics:

It is possible, I think, to indicate a general pattern for the relation of natures to meanings where the nature is not given by the meaning. What is given by the meaning, or perhaps 
more broadly by the use of the words, is a role that the nature is to play. If there is a single candidate that best fills the role, that will be the nature of the thing. (Adams 1999: 16)

As mentioned before, Adams contends that the role picked out by our talk of goodness includes being the object of admiration, desire, and recognition. The best candidate to play the role, argues Adams, is "the divine nature" (28). He rejects, for instance, Richard Boyd's naturalistic account of the nature of goodness, but a discussion here of Adams' version of a sort of open-question argument (77-82) would take us too far afield. This article will claim that something's goodness consists in resemblance with the platonic good, but remain neutral about whether the latter is God. Suffice it for our purposes at this point to know that Adams uses what we could call a conceptualrole semantics of goodness that allows him to connect that semantics to its metaphysics, while at the same time leaving room for a distinct metaphysical account of the nature of the platonic good. 2. Being good: What an individual's goodness holds in virtue of, Part 1.

Before tackling the question of what something's goodness holds in virtue of, let me begin by introducing some preliminary terminology. If some fact x obtains solely in virtue of a different fact $\mathrm{y}$, then the latter is the determinant of the former, and if y obtains, so does x. If fact $a$ obtains in virtue of fact $b$ and some other fact $c$, then $b$ and $c$ are both partial determinants of $a$, and $a$ is partly in virtue of $b$ (and also partly in virtue of $c$ ). Thus, if both these partial determinants obtain, so does $a$. I will argue that for any individual $\mathrm{x}$ belonging to a kind, x's goodness holds in virtue of two partial determinants: a platonic determinant, and a kind-based determinant. In addition, I will contend that its goodness is necessarily in virtue of those two partial determinants, and so if $\mathrm{x}$ is good, both the platonic and kind-based determinants obtain. In other words, it would be a mistake to think that the answer to what something's goodness holds in virtue of, can leave out either of the two determinants.

Before showing that something's goodness must hold partly in virtue of satisfying the platonic good in some way, I will first argue it must hold partly in virtue of satisfying a kindindependent standard. Mark Murphy offers an interesting argument to hold the latter claim by showing that it is a mistake that something being good is solely in virtue of satisfying kind-based standards. He asks us to imagine "a lesser god" who creates a being that is designed to be ignorant, friendless, and unable to appreciate beauty.

A lesser god might fashion a being that ought not to --- that is, it would be defective with respect to its design plan if it came to --- know things, or to make a friend, or to appreciate something beautiful. But we would resist the view that these things are admirable or lovable just by exhibiting the features being dead or being ignorant or being friendless. (Murphy 2011: 160, italics not added.)

For simplicity, let us focus on the feature of ignorance. Being ignorant is intuitively not a good feature even if possessing it fulfills that being's "design plan" and thus also satisfies its kind-based standard. Murphy's point is that on Aristotelian accounts, on which something's goodness holds solely in virtue of satisfying its kind-based standards, it would follow that the being's ignorance is good. But intuitively, being ignorant is not. Murphy does allow that good can come of ignorance, death, and the like, but argues they are not good for their own sakes, but for the avoidance of something worse or for the sake of something better. Thus, something's being good must also be partly in virtue of its somehow satisfying kind-independent standards. ${ }^{1}$ Elsewhere, this conclusion

\footnotetext{
${ }^{1}$ Murphy's platonism about goodness is also a theistic one, in that the platonic good is God, as we shall see later.
} 
has also recently been argued using a different counterexample. Berman Chan (forthcoming) offers the example of a hypothetical Ebola-like microbe, whose kind-based standard of goodness requires it to destroy other organisms for the sake of destruction.

The Ebola-like microbe is a counterexample to the Aristotelian account because it is bad when it performs its functions. We know by intuition that a functioning Ebola-like microbe is bad --- we know that something is (non-instrumentally) bad which functions to ravage mammals by rapid infection, for the sake of destruction. (Chan forthcoming)

However, on the kind-based account of what in virtue of which something is good, that microbe would be good simply because it satisfies its kind-based standard, which includes a requirement to destroy for its own sake. ${ }^{2}$ Hence, the counterexamples show that satisfying a kind-independent criterion is needed for something's goodness to obtain.

At this point, the question might arise why we should not just say that being good is solely in virtue of meeting a kind-independent standard, without a member's goodness being even partly in virtue of satisfying its kind-based standards. I think there is a good reason to resist this further move. To demonstrate this, I will follow two writers, William Fitzpatrick and Murphy, who each offer arguments in this connection which I will show are quite similar at core. Let us begin with Fitzpatrick (2008), who argues that something's being good is in virtue of not only the thing's properties, but also the fact that possessing those properties is such as to satisfy standards of goodness for that kind. He gives the example of a good computer, which is good in virtue of booting up quickly, running at a high speed, etc. Fitzpatrick lets "XYZ" stand for these properties that are reasons that the computer is good, and in so doing we realize XYZ are good-making properties. Following Jonathan Dancy, Fitzpatrick recognizes that something's goodness is a resultant property, and the thing's good-making features are the resultance base. ${ }^{3}$ But, as Fitzpatrick asks, what is the relationship between the former and the latter? While one might initially think that the computer's goodness holds solely in virtue of its base properties obtaining, Fitzpatrick disagrees. We can see that its being good is not only in virtue of its possessing XYZ because many other things can have them without being good:

Does [the fact that the thing is good] consist simply in the fact that it has XYZ? One clear indication that it does not is that any number of things could have XYZ without being good. This is generally true for good-making properties of artifacts: sharpness makes for goodness in a knife, for example, but not in a pair of glasses. [...] In the present case, the point is that the fact that this computer is good consists not only in the fact that it has XYZ, but in this together with the fact that possessing $\mathrm{XYZ}$ is such as to satisfy the standards of goodness $\mathrm{S}$ for computers. (Fitzpatrick 2008: 186)

Fitzpatrick argues persuasively that an individual thing's being good holds not merely in virtue of XYZ but also partly in virtue of "the fact that possessing XYZ is such as to satisfy standards" for the kind. For brevity, I will also simply call this second fact 'the standards for the kind', although this

\footnotetext{
${ }^{2}$ Chan also argues that destruction for its own sake (not only maintenance and reproduction) can be part of a species' teleology. Further, he argues that if an Aristotelian contends that they offer an exhaustive account of goodness, and Chan argues that neo-Aristotelians like Philippa Foot do (Chan 7-9), then the ignorant being and Ebola-like microbe are arguably counterexamples to Aristotelian accounts of goodness, as such an account claims that satisfying kind-based standards is the sole determinant of a member's goodness.

${ }^{3}$ See Dancy (1993: 73-7) and Dancy (2004: 232)
} 
fact is strictly speaking a relation holding between $\mathrm{XYZ}$ and the kind-based standards. ${ }^{4}$ The relation holds just in case possessing XYZ is required by the kind-based standards (hereafter ' $\mathrm{K}$-standards').

Similar to Fitzpatrick's argument is Murphy's "chicken fried steak" argument:

Suppose that I come down with a rare disease. Interestingly, the symptoms of this disease include my muscles taking on the taste and consistency of a piece of deep-fried tenderized round steak, my epidermis becoming crisp, like buttermilk-and-egg-saturated flour dipped into hot oil, and my pores oozing a whitish substance that is peppery and creamy. I begin to share the properties that make a properly-prepared chicken fried steak good. But this does not make me better, not in the least, or in any way. (Murphy 2011, 155)

The properties which make for a good chicken fried steak just are not the ones that make for a good human. What solves this "chicken fried steak problem" is recognizing that the kind to which an individual belongs determines whether certain properties can be good-making ones. Humans are just not the kind of thing which are good by having crispy and tasty skin oozing with a peppery and creamy substance, "though it surely is what makes a chicken-fried steak good". He continues, "[m]y view is that whenever a being belongs to some kind, then the standards for excellence for that thing are fixed in part by its kind." (Murphy 159)

These examples by Fitzpatrick and Murphy both support the conclusion that an individual's being good holds partly in virtue of kind-based considerations. Call their line of reasoning the kinddependence argument. This argument has used examples featuring artifacts, but the scope of my inquiry is actually meant to focus on living things belonging to kinds, and the above examples of artifacts were meant to shed light by analogy upon the evaluation of living things. A similar argument can be offered to show that an individual living thing's goodness is partly in virtue of satisfying kind-based standards. In fact, Philippa Foot's neo-Aristotelian account of "natural goodness", which we will examine more closely later, gives such an argument in a backhanded manner. She points out that cooperative hunting is required for the wolf, and swiftness for the deer (2001: 34). It seems to me that one could then go on to argue that activities good-making for the wolf (e.g. cooperative hunting) are not so for the deer. So, satisfying kind-based standards does figure into the wolf's or deer's being good. Further, this result reasonably holds for other kinds of living beings --- the conclusion about the wolf and deer held not due to peculiarities of their particular kind. Instead it is more plausible that the result obtained because the relevant things are members of some kind, and are held to the relevant kind-based standard. So, it is reasonable to generalize, and conclude that for any individual $\mathrm{x}$ that is a member of kind $\mathrm{K}$, $\mathrm{x}$ 's being good is partly in virtue of satisfying standards for $\mathrm{K}$.

Of course, as argued earlier, an individual x's being good is also in virtue of a kindindependent determinant, in addition to being in virtue of x's base properties and K-standards. I claim, then, the following thesis $\mathbf{F}$ :

F: The goodness of any individual $x$ (belonging to kind $\mathrm{K}$ ) holds in virtue of both kind-based and kind-independent determinants.

\footnotetext{
${ }^{4}$ Fitzpatrick also sometimes calls this fact simply "standards". See, also for example: "It consists rather in that fact [about the individual possessing XYZ] together with the facts that there are appropriate standards of goodness $\mathrm{S}$ for human behavior and that actions that exhibit the features in the resultance base in question [....] violate those standards" (Fitzpatrick 2008: 187-8).
} 
Adding the kind-independent determinant affords us theoretical resources to explain the goodness (or badness) of not only individuals belonging to actual kinds, but also individuals belonging to hypothetical but metaphysically possible kinds, such as the ignorant being or Ebola-like microbe. Though the microbe bears properties satisfying its K-standards, the kind-independent determinant would not obtain with respect to the microbe, because its activity is destructive for its own sake and thus does not satisfy that determinant (as I will elaborate upon later). But because of the kind-based determinant, we are also able to explain why a human that begins to share the properties that make a tasty chicken fried steak good is nonetheless not good; this is because that human does not possess base properties that satisfy its K-standards. Thus, the explanatory power of our account, being able to explain the goodness or badness of ordinary as well as hypothetical things, constitutes a good reason to accept it.

Additionally, it seems to me that the kind-independent determinant should be understood along platonic lines. The account of goodness that we are after in this discussion is an account of the goodness of individuals. It is neither the goodness of such individuals construed as usefulness nor what is good for them (well-being), but rather their goodness that is their excellence. First, goodness as what is good for individuals, such as receiving proper nutrition, etc., pertain to certain objects or activities that the individuals need, that those objects or activities are good for the individuals. However, the goodness as excellence that my account seeks is after the goodness that pertains to individuals, regarding the individuals themselves being excellent. Second, from my focus being upon the excellence of individuals, it should be inferred that the relevant kind-independent determinant for such an account of something's goodness should not be consequentialist. After all, on contemporary consequentialist theories the primary bearers of goodness are states of affairs, since whether actions (or rules, motives, even individuals) are good derives from the goodness of their consequences, which are states of affairs. As Adams points out, however, states of affairs (unlike individuals) are not the sort of things that can bear the property of excellence, as they lack the required unity to bear it (17). So, the excellence of individuals cannot be derived from states of affairs as the latter cannot possess excellence. Platonic and consequentialist theories are the most plausible accounts of kind-independent value, but I have just rejected a consequentialist account. Thus, it is reasonable to accept a platonic account of the kind-independent determinant of the excellence of individual things. That is, for this kind-independent determinant to obtain is for the individual to somehow resemble a platonic entity. More precision about this determinant will be developed in a later section, but for this we must first discuss what x's being good consists in, before returning later to continue our discussion of what it obtains in virtue of.

\section{Being good: What an individual's goodness consists in}

Having discussed what being good is in virtue of, I now turn to the distinct question of what being good consists in. This question concerns the metaphysical status of something's being good. In this section, I will argue that being good is to be good platonically.

For an individual's goodness to be good platonically is for its goodness to consist in its resemblance of the platonic good. Call this the good platonically thesis. In contrast, for an individual's goodness to be good in a kind is for its goodness to consist in its being good as a member of its kind. Call this the good in a kind thesis. It may be possible that x's goodness consists in both platonic goodness and goodness in a kind, but then goodness would be less unified and this third thesis strikes me as implausibly complicated, thus I will not consider it any further. Given that in an earlier 
section I argued for $\mathbf{F}$ that something's goodness is in virtue of both kind-based and kindindependent considerations, let me ask the preliminary question of whether $\mathbf{F}$ is even compatible with goodness consisting in being good platonically. Is someone who endorses such a claim able to concede a side condition that x's goodness (which is claimed to be platonic) obtains also in virtue of the obtaining of a kind-based determinant (as claimed in F)? Conversely, consider the view that x's being good consists in its being good in a kind. Could someone endorse this claim while maintaining $\mathbf{F}$, that x's goodness (which is as a member of its kind) obtains also in virtue of the obtaining of a platonic determinant?

Let us begin with the "preliminary question" posed above. Here I think that x's being good platonically is indeed compatible with x's goodness being partly in virtue of x's satisfying Kstandards, because what it is for $\mathrm{x}$ to resemble the platonic good could depend on kind-membership in some way, such as in determining the context for resemblance. Now, first, as we have seen, Adams contends that a thing (besides God) being excellent consists in being good platonically. He identifies the platonic good with God, and claims a Godlikeness thesis that "other things are excellent insofar as they resemble or imitate God." (28) Murphy consciously follows Adams' account's "central distinctive feature" here, agreeing that "the goodness of creaturely goods consists in their resemblance to God" (Murphy 150), and thus Murphy also holds what I have called the good platonically thesis, as well as Adams' view that the platonic good is God. Further, Murphy accepts Adams' point that not every shared property counts as resemblance, but the context of property sharing does matter. But Murphy criticizes Adams' explanation of this holism, that it consists in resembling God such that it "could serve God as a reason for loving the thing" (Adams 36). Murphy thinks that this sort of condition for resemblance is "explanatorily pretty useless", not specifying what would give God reason to love something. Instead, he believes that the solution is to fix what it is to resemble God as what the thing "ought to become" qua member of its kind. "It is the kind that fixes the context for determining what counts as a relevant resemblance or failure to resemble, God. Every good, then is a divine likeness, but those that make a thing good are those divine likenesses such that members of the kind ought to exhibit them." (Murphy 160) Thus, although he disagrees with Adams' explanation of what context of resemblance is relevant, Murphy does agree that being good is to be good platonically, where God is the Good.

I follow Murphy (and Adams before him) in thinking that goodness consists in being good platonically, and also follow them in understanding x's being good platonically as x's resemblance of the platonic good (without claiming the latter is God). Also, as both Adams (32) and Murphy (150) recognize, resemblance is holistic. It seems to me, however, that Murphy is correct that kindmembership is what plausibly and substantively supplies the proper context for an individual's resemblance to the platonic good. I contend, then, that the good platonically thesis is compatible with x's goodness being also partly in virtue of satisfying its K-standards. Furthermore, so far the good platonically thesis is a plausible one to hold.

However, the question now arises why we should not think that being good consists in being good in a kind instead, while allowing for a side-condition that something's being good holds partly in virtue of a kind-independent determinant. Perhaps Murphy and Adams claim that x's goodness consists in being good platonically because they endorse a theistic platonism of goodness. As Murphy writes, "God is at the center of the normative world, not just one object of love among others, but both object of, and standard for, admiration." (Murphy 2011: 160). But any sort of theistic argument to embrace x's goodness as consisting in being good platonically is unavailable to 
my account. So, I offer a different motivation, that accepting the good in a kind thesis leads to a significant implausibility. This is the implausibility that something bad, like an Ebola-like microbe that satisfies its kind-based standards, would not even be good in a kind. Let us unpack this.

Suppose that the goodness in a kind thesis is true. Just as a defender of the good platonically thesis would also hold that what it is to resemble the platonic good will partly depend on satisfying kindstandards, in order to be consistent with $\mathbf{F}$, a defender of the goodness in a kind thesis would also hold that what it is for an individual $\mathrm{x}$ to satisfy kind-standards will partly depend on its somehow resembling the platonic good. So, some $\mathrm{x}$ that does not resemble the platonic good is not good even if it were to satisfy its kind-based standards. This is simply the lesson of the Ebola-like microbe example. However, the result is that contending that being good is being good in a kind would have the implausible implication that this microbe fails to even be good in a kind. But it is reasonable to think that being good in a kind is to satisfy kind-standards (just as being good platonically is to resemble the platonic good). So, since the properly functioning microbe is bad and on this supposition that something's goodness consists in goodness in a kind, it would follow that the microbe would be deemed to fail its kind-based standards. But this contradicts the fact that the functioning microbe does meet its kind-based standards. Thus, the good in a kind thesis is implausible. Now, something's kind-standards could resemble the platonic good (as I will defend later), and so something could be good if (and only if) it satisfies its kind-standards that do resemble the platonic good. However, for things like the microbe, their kind-standards do not resemble the platonic good. Thus, the implausibility remains for things like the microbe, that on the good in a kind thesis, a member meeting its kind-based standards would not even be deemed good in a kind.

The good platonically thesis does not share this problem. This thesis claims that x's goodness consists in its resemblance to the platonic good. However, in order to be consistent with $\mathbf{F}$, what it is to resemble it will partly be in virtue of x's satisfying kind-based standards. So, some $\mathrm{x}$ that does not satisfy its kind-based standards is not good. This is the lesson of Murphy's chickenfried steak example where the human that becomes more and more like a good chicken-fried steak is not good. On the good platonically thesis, this human does not resemble the platonic good. This is plausible, as we argued earlier that it is plausible that kind-membership sets the context within which any x resembles the platonic good. Now consider the Ebola-like microbe example. Though it satisfies the standards laid down by kind-membership, the kind-independent determinant does not obtain, and so such a microbe is not good. On the good platonically thesis, it would follow that such a microbe does not resemble the platonic good. This too is plausible. Upon quick reflection, one can also see that the good platonically thesis does not result in implausibilities when analyzing members of run-of-the-mill kinds such as the oak and the squirrel. Thus, because the good in a kind thesis runs into the implausibility explained earlier, it is more plausible to hold the good platonically thesis. Now, of course more detail needs to be provided to explain exactly in virtue of what something resembles the platonic good, and to explain, for instance, why an oak does but a microbe does not (though they might both satisfy their kind-standards). I will take up this question now.

\section{Being good: What an individual's goodness holds in virtue of, Part 2}

Having developed what being good consists in, we are now in a better position to answer with greater precision the question of what x's being good is in virtue of. I submit that an individual's being good obtains in virtue of three determinants as expressed by the following: 
G Individual $\mathrm{x}$, member of kind $\mathrm{K}$, is good in virtue of exactly the following partial determinants: $\mathrm{x}$ 's base properties B, B being such as to satisfy kind-based standards (K-standards), and the K-standards resembling the platonic good.

G should be understood as the claim that x's goodness holds necessarily in virtue of those three determinants. As such, not only is it the case that if all three determinants obtain, so does x's goodness, but also that it must be that if $\mathrm{x}$ is good, all three determinants obtain.

The final determinant listed in $\mathbf{G}$ is the fact that the K-standards resemble the platonic good. It is tempting to have claimed instead that this final determinant should be the fact that the individual $x$ itself resembles the platonic good, given that I argued that x's goodness consists in being good platonically. Granted, given the good platonically thesis, x's goodness is in virtue of its resembling the platonic good, and the latter is a sole (not merely a partial) determinant of the former obtaining. However, it is also definitional, and provides no further explanation of what x's resemblance of the platonic good is in virtue of. So, in a way our question in this section asks what x's resemblance of the platonic good holds in virtue of. Now, if one were to answer that it holds solely in virtue of x satisfying its $\mathrm{K}$-standards, we saw earlier that this is not tenable for all kinds $\mathrm{K}$ since the standards for certain $\mathrm{K}$ such as the Ebola-like microbe do not satisfy (i.e. resemble) the platonic good. Well, what if we also require that the K-standards resemble the platonic good? In that case then, and below I will discuss how a standard could resemble the platonic good, we would claim that x's being good is partly in virtue of its satisfying $\mathrm{K}$-standards and partly in virtue of those standards resembling the platonic good. Notice, then, that this is what G claims, and it is plausible.

\subsection{K-standards resembling the platonic good}

What is it for the $\mathrm{K}$-standards to resemble the platonic good? I will argue that the $\mathrm{K}$ standards resemble it firstly with respect to requiring activities, as the platonic good will be posited to be active, and must resemble it secondly also at the level of what teleology those activities are directed towards.

Let us first take a closer look at K-standards, in order to better understand the activities expressed by them and the teleology of those activities. I think a plausible account of the Kstandards can be found in the Aristotelian naturalism offered by Michael Thompson (1995) and Philippa Foot (2001). It is perhaps not necessary to embrace their account rather than some other kind-based theory about what goodness is in virtue of, but I will use their plausible account to make more concrete our discussion of what I have called the K-standards, and a kind-based account more broadly. At the core of the account is what Thompson calls "the representation of life". For any creature that we could represent as living, there is a corresponding "interpretation or understanding of the life-form shared by the members of that class" (Thompson 1995: 288). All of a particular creature's activities, for instance hunting, eating, or reproducing, are to be recognized as such only by using an understanding of a lifeform, and representing that individual creature as a bearer of that form.

Such an interpretation and understanding of the species are articulated as Aristotelian categoricals, propositions which express the characteristic activities and features of this species. Stock examples of Aristotelian categoricals are the oak has broad roots, the tiger has four legs, the squirrel gathers acorns, and so on, depending on the kind. However, Aristotelian categoricals are also teleological, in the sense that they do not articulate generalizations about members of a kind merely 
having certain features or doing certain activities, but pick out those features and activities that relate to the proper ends of that kind. Thus, Foot writes:

[W] hat distinguishes an Aristotelian categorical from a mere statistical proposition [...] is the fact that it relates to the teleology of the species.[...] This is why the noise made by the rustling of leaves is irrelevant in this context while the development of roots is not. And this is why Aristotelian categoricals are able to describe norms rather than statistical normalities. (Foot 2001: 33)

Foot identifies species-teleology as species-characteristic ways of seeking: self-maintenance and reproduction (2001: 31), and in the case of humans, reason-following (2004: 11-12). As the categoricals pick out features and activities that relate to the proper ends of the relevant kind, the categoricals can form the basis for kind-specific norms of goodness, and thus provide the basis for evaluation (2001: 34). Also, it strikes me as plausible that these kind-specific norms are what Kstandards are. As there are many norms per kind of lifeform, the K-standards can be understood as a set of numerous norms corresponding to that kind's numerous Aristotelian categoricals (e.g. the squirrel gathers acorns, the squirrel moves on four legs, etc.). What is the relevant part of a given Aristotelian categorical with respect to which it can resemble the platonic good? The categoricals are propositions that express lifeform-related features or activities (and there is a case for understanding them primarily as expressing activities). ${ }^{5}$ These activities are contained in the propositions as concepts. Take the Aristotelian categorical for the squirrel just mentioned, the squirrel gathers acorns. The relevant activity and corresponding concept contained here pertains to gathering acorns. Its K-standard resembles the platonic good, we might think, with respect to the standard's requirement of this activity of gathering acorns.

Murphy had stated that good features are "divine likenesses" that members of the kind ought to possess (Murphy 160). Clearly, the ignorance of Murphy's ignorant being was not a platonic likeness, and we might think at first this owes to the implausibility that the platonic good (conceived as God) is ignorant. But how exactly does gathering acorns count as an activity that is a platonic likeness, as the platonic good does not gather acorns? Murphy does not have space to answer this sort of question. I will argue that yes, the squirrel's K-standard can resemble the platonic good. But it is not as simple as resembling it with respect to the particular activity of gathering acorns, because, again, it is implausible that the platonic good gathers acorns, or has four legs. Rather, it seems that the K-standard can resemble the platonic good with respect to something more general about the activities required by the K-standard. After all, if that K-standard resembled it with respect to gathering acorns itself, keep in mind that the squirrel's other categoricals include moving with four legs and a bushy tail, seeing with eyes of certain sort, climbing tree trunks using a certain claw and foot technique, travelling on branches using a certain technique, etc. Now if the squirrel Kstandard resembled the platonic good with respect to these specific activities themselves, the platonic good would appear to be more and more like a squirrel. ${ }^{6}$

\footnotetext{
${ }^{5}$ Chan argues (following Aryeh Kosman [2013: 122]) that what something is, that is what is included in a lifeform's representation of life, is a positive work (ergon). Thus, the categoricals should express activities, and features (e.g. the squirrel's four-leggedness) should be understood as categoricals in adverbial form, e.g. the squirrel gathers acorns four-leggedly (Chan 13 fn. 14).

${ }^{6}$ Even apart from this absurdity, even though it should be recognized that such a "platonic good" would at least do the theoretical work needed to assess the goodness or badness of individual squirrels, it would nonetheless fail to work for individuals of other lifeforms, unless there were a multitude of platonic goods. But it is more plausible that
} 
Instead, it is more reasonable that K-standards can resemble the platonic good with respect to something more general about the activities required by the K-standard, and that is their simply being an activity. So, this is why earlier I signaled that I would claim that the K-standards resemble the platonic good with respect to requiring activities. Now, for this claim to be plausible, I will need to claim two further theses. The first thesis is a metaphysical assertion that the platonic good is active, by being a concrete (but not physical) individual that is active. The second thesis is that $\mathrm{K}$ standards also resemble the platonic good at the level of what their required activities are directed towards ("species-teleology"). This account retains the importance of the context of kindmembership in determining resemblance, as species-teleology is set by kind-membership.

Let us begin with the first thesis that the platonic good is active. This thesis allows us to form the working hypothesis that the squirrel's K-standard resembles the platonic good with respect to the activity qua activity that is required by those standards. This hypothesis would also easily explain how the K-standards of the oak or the beaver would resemble the platonic good, as the Kstandards of all lifeforms do express activities. This thesis would also provide a basis from which to explain in what sense the K-standards of the cockroach, which eats garbage and sewage waste, resembles the platonic good. The explanation is that the resemblance is not with respect to the cockroach's eating of those disgusting things, but in its eating them qua activity.

However, more must be said. Indeed, at this point it must be recognized that with respect to its activities qua activity, even the destruction-aimed activities contained in the K-standard of the Ebola-like microbe would resemble the platonic good, as the microbe surely destroys via activity. Nonetheless, one can continue the trajectory of our analysis to show that the K-standard of the microbe does not resemble the platonic good like the oak or squirrel does, for the following reason. The microbe's K-standard, besides requiring that a member engages in activities with the teleology to self-maintain and reproduce, they also require some activities that have the teleology to destroy (for its own sake) neighbouring organisms. On the other hand, I have postulated that the platonic good is active. The rabbit's K-standards require activities directed at self-maintenance and reproduction, and these ends can reasonably be understood more broadly as the ends of continued activity. It is plausible to posit that the platonic good is not only active but continually active. Now, the rabbit teleology's state of continuing activity will be of a different nature than the continuing activity of the transcendent platonic good. Consider for example that the rabbit's continuing activity is not eternal. In addition, as each species achieves its teleology in ways unique to its kind, the very nature of that activity will be different than that of the platonic good. Nevertheless it is reasonable that the rabbit's teleology of "creaturely" continuing activity resembles the platonic good's continuing activity, as the former is a state of activity and indeed continued activity. Thus, the Kstandard of the rabbit resembles the platonic good, at the level of the teleology of activities required by that K-standard. ${ }^{7}$

the platonic good is a unity because if the platonic good were a multitude of platonic goods, this would really be to posit merely kind-based standards instead of a single kind-independent standard, which is also required by $\mathbf{F}$.

${ }^{7}$ Metaphysically, how can a standard resemble the platonic good? My answer: the K-standard has teleological attributes, and on that basis the K-standards can resemble the platonic good. How can it bear attributes? The Kstandard of a given kind are a set of Aristotelian categoricals, which are propositions. Every true Aristotelian categorical must be directed towards at least one species-telos (end, such as self-maintenance, etc.), and so teleology is indeed an attribute of each categorical, and in this way, of the K-standard. How exactly? A proposition such as the rabbit eats dandelions could bear the following property: expresses an activity directed at self-maintenance. 
When it comes to the Ebola-like microbe, however, rather than having activities aimed at continued activity, it has activities directed towards destruction for its own sake, that is, the cessation of activity of the microbe's victims, for cessation's sake. But the platonic good is active. Thus, the microbe's K-standard, requiring activities directed at destruction for its own sake, does not resemble the platonic good at the level of what those activities are directed towards. So, the second thesis I claimed earlier, that a K-standard must resemble the platonic good also at the level of what teleology the activities (required by that standard) are directed towards, is able to plausibly account for why the microbe's K-standard does not resemble the platonic good while that of the oak or squirrel does. ${ }^{8}$ Thus, this is a good reason to accept that thesis.

Now, the K-standard of a plant eater such as the rabbit will require activities which also destroy plant lifeforms. However, the rabbit's activity here is directed toward its species teleology of nutrition and not destruction. In other words, the rabbit "destroys" its food for the sake of its nutrition and self-maintenance. By contrast, the microbe's K-standard includes activities aimed at destruction for its own sake, in addition to whatever ends it has pertaining to self-maintenance and reproduction. Granted, the K-standard of the microbe does have some resemblance to the platonic good at the level of its activities' other teleologies of self-maintenance and reproduction. But the directedness of its destructive activity is simply contrary to the nature of the platonic good, the cessation of activity for cessation's sake being contrary to its active nature. Thus, the resemblance of the microbe's K-standards to the platonic good is negligible, and I argue that such a microbe satisfying its K-standards would be bad.

Now, it might be asked why the platonic good's nature is not destructive for its own sake. Setting aside metaphysical questions about whether it even makes sense for the platonic good to have this nature, ${ }^{9}$ one could offer a semantic argument that the successful candidate for the platonic good cannot. As Adams argues, "a property that belonged mainly to things that almost all of us have always thought were bad would surely not be filling the role picked out by our talk of 'goodness."' (20) Surely, being sadistic or loving cowardice (Adams 46) are properties belonging mainly to things almost universally deemed always bad, and something bearing those traits could not play the role

\footnotetext{
${ }^{8}$ An objector might complain that the microbe's activities do not undermine its own continued activity, but others'. Thus, so the objection goes, the end (telos) of the microbe's activities is not inconsistent with anything in the platonic good's nature, as the latter's activities are self-continuing. It could be responded, however, that it is the telos (e.g. continued activity, cessation of activity, etc.) and whether that corresponding state resembles the platonic good that is relevant, rather than whose state is concerned (e.g. the microbe, its victims, or etc.) After all, it is plausible that a Good-resembling K-standard has activity directed towards a telos like continued activity, regardless of whether the corresponding state concerns the same individual (in the case of self-maintenance), another member of the kind (e.g. in the case of reproduction), or hypothetically that of some other kind. By the same token, if the Kstandard of some $\mathrm{K}$ has activity directed towards the cessation of activity for its own sake, it is plausible the standard would not resemble the platonic good whether this destruction is directed towards the cessation of activity of self, other members of the kind, or of other kinds.

${ }^{9}$ Nothing I have posited so far about the platonic good's nature, that it is a concrete exemplar that is active, indicates (nor precludes) that it could destroy something else for destruction's sake. Supposing it could, then it would not destroy for the sake of self-preservation. But then the question arises as to why its nature should not also be applied to itself, and so destroy itself for destruction's sake. Such an account of the platonic good would be a non-starter. Perhaps though, however (strangely), it possessed the causal powers to destroy others but not itself. Or, it could harm itself without ever completely destroying itself, though always tending to it without attaining it (like how the value of the function $1 / \mathrm{x}$ always tends towards but never reaches 0 as the positive value of $\mathrm{x}$ increases.)
} 
picked out by our talk of goodness. It seems to me that one should say the same about something that is destructive for its own sake. So, something whose nature was destructive for its own sake would not be a successful candidate to fill the role picked out by our semantics of 'good'. Thus, whatever the platonic good is will not have that nature.

4.2 Can different K-standards that resemble the platonic good resemble it to varying degrees?

We have seen that the K-standard of something like the Ebola-like microbe does not resemble the platonic good (or only negligibly resembles it). In contrast, the K-standards of other lifeforms such as the oak or squirrel do resemble the platonic good. Of the lifeforms whose Kstandards do resemble the platonic good, do some resemble the platonic good more than others do? I will argue that the K-standards of different kinds can be ranked further with respect to greater resemblance with the platonic good. Along what lines? I think this question (call this the ranking question) can be answered in different ways that are compatible with the basic account offered so far.

I will in the following suggest one answer to the question. This answer, call it the teleological-diversity response, will argue that some K-standards compared to others require activities directed at more different ends, such that these more "teleologically diverse" K-standards, at the level of those ends, could resemble the platonic good more than the other K-standards do. It is reasonable that the K-standard for the human is more teleologically diverse than the K-standard for the squirrel, because the former expresses activities directed towards the same ends as the Kstandards of the squirrel, but in addition also expresses mental activities directed towards the telos (end) of rationality. It may be obvious that humans have this additional telos, but it is instructive to examine Foot's argument because it seems to me that her argument can be more widely applied to fill out the answer to the ranking question.

Foot argues that the teleology of the human, the human good, can be articulated by reflecting on the things without which the human would be deprived. Humans need "the mental capacity for learning language; they also need powers of imagination that allow them to understand stories, to join in songs and dances -- and to laugh at jokes. Without such things human beings may survive and reproduce themselves, but they are deprived." (2001: 43) Foot is correct that humans have an additional telos that, if they lacked, they would be significantly deprived, even if for the sake of argument they could self-maintain and reproduce without rationality. So, due to what we might call the deprivation principle, the species-teleology of the human should be broadened to include the end of rational activity.

With the door thus widened, and using the same deprivation principle, we might also see that animals such as the squirrel (and the human) would be deprived by a lack of perceptual activity, even if they may survive and reproduce themselves. So, and here I am speaking for myself and not Foot, that due to the deprivation principle, we can claim this: in addition to self-maintenance and reproduction, the species-teleology of perceptual animals should be broadened to include the end of perceptual activity. In addition, let us posit that the platonic good is not only active and continually so, but also engages in something like perceptual activity (e.g. thinking thoughts with representational content) and also rational activity. I will elaborate briefly on this posit in the final section. Making this posit allows us to answer the ranking question in a plausible manner. For instance, because the K-standard of the squirrel represents activities directed towards the same ends as the K-standards of the oak (continued activity) but also perception, the K-standard of the former 
is more teleologically diverse than the latter. Thus, at the level of teleology, the K-standard of the squirrel resembles the platonic good more than the oak's K-standard resembles it (the platonic good). In the same way, since the K-standard of the human represents activities directed toward the same ends as the K-standards of the squirrel but also the end of rationality, the K-standard of the human is more teleologically diverse than the squirrel's. Thus, the K-standard of the human resembles the platonic good more than the squirrel's K-standard resembles the Good.

Clearly, this classification of activities is influenced by the Aristotelian schema of the different capacities of the soul: nutritive, perceptive, mind, etc. In addition, in assessing a given Kstandards' resemblance to the platonic good, let me be clear that it is not that activities directed towards rationality are given more weight than those aimed at perception, which are in turn weighted more heavily than those directed towards self-maintenance and reproduction. Rather, the claim is that given two K-standards that at the level of their expressed activities' teleologies both resemble the platonic good, the more teleologically diverse K-standard will resemble the platonic good more. Finally, keep in mind that this is but one sort of answer to the ranking question, and my basic account of how K-standards resemble the platonic good could be compatible with many different answers.

Whatever the answer to the ranking question, this section has demonstrated that for any individual x, member of kind $\mathrm{K}, \mathbf{G}$ gives the partial determinants that x's goodness is in virtue of. One way of looking at what $\mathbf{G}$ provides us is an account of what an x's resemblance with the platonic good is in virtue of, namely x's satisfaction of its kind-based standards as long as those K-standards resemble the platonic good. As well, the section has explained the basis of this resemblance, claiming it is based firstly upon resemblance with respect to the $\mathrm{K}$-standards requiring activities, and secondly upon resemblance at the level of those activities' teleologies.

\section{The Platonic Good}

On my platonic kind-based account of goodness, what more can we say about the nature of the platonic good? In other words, what more is true about this platonic good that the account posits?

I have claimed that the platonic good is something active, and indeed my preference throughout has been that it is a concrete (though not physical) individual rather than a property. I will now give some motivation to think this. The two options parallel what Adams alluded to as two distinct strands in Plato's thought about the Forms: one in which they are primarily exemplars, the other in which they are properties or universals (14). Applied to the Form of the Good, the first understands it as a non-abstract exemplar of goodness, the second as the property of goodness. Call these claims about the platonic good the exemplar thesis, and property thesis, respectively. These options are each compatible with the semantics of 'good', as the question of which option to accept pertains to the metaphysics (nature) of goodness. With respect to the platonic good being active in some way, which is a further claim about its nature, the exemplar thesis can easily accommodate this further claim by understanding the Good as an individual that is active. If one accepted the property thesis, K-standards could instantiate the good rather than resemble it. K-standards instantiating the good could hold in virtue of requiring activities directed towards species-ends that instantiated the property of goodness. However, on this property thesis it would not be straightforward what the metaphysical relationship would be between the platonic good and the property of being active, and thus not clear why activities instantiate goodness and why activities directed toward certain species- 
ends would instantiate it more than others. If we claimed that the property being good and being active were identical, this would be metaphysically problematic or complicated at best-----perhaps the property of goodness reduces to (or is partly composed of) the property of being active, or vice versa. Holding the exemplar thesis instead would be less troublesome metaphysically.

Alternatively, what if someone maintaining the property thesis does not claim that being good and being active are identical, but being good is a higher-order property, and so being active can itself instantiate goodness. So, for instance, the K-standard of the oak requires activities that are directed toward continued activity, and thus that K-standard instantiates being active, which instantiates being good. And so, that K-standard instantiates goodness. However, first, it is implausible that K-standards themselves could be active, and second, even if they could, it would not follow that the K-standard would instantiate being good (as something instantiating a property does not necessarily instantiate the higher-order property the first property instantiates.) Now, it would seem that for any property, be it being active, being pleasurable, or any other property that might be thought to help explain why a K-standard instantiates goodness, the same problem of explaining the metaphysical relationship between it and goodness would arise. So, one might think that no other property should be proposed to explain why a K-standard instantiates goodness, but instead a Kstandard like the microbe's just does not instantiate it while something like the oak's does. However, then the relation between K-standards and the platonic good would be brute. Instead, holding the exemplar thesis would allow for an explanation for the relation, as given in the pages above. In addition, the exemplar thesis allows for a relationship between being active and the platonic good that is not metaphysically problematic: the platonic good is a concrete thing that is active. So, accepting the exemplar thesis is preferable.

In the previous section, I raised the "ranking question" of how, of the various kinds whose K-standards do resemble the platonic good, how these K-standards of different kinds can be ranked further with respect to greater resemblance to the platonic good. My account had already claimed that K-standards' activities directed at the telos of self-maintenance or reproduction should be understood more broadly as activities directed at continued activity. At the level of this teleology, I argued that the K-standards resemble the platonic good, which I posited to be continually and eternally active. My teleological-diversity response had included a peripheral claim that K-standards' activities directed at perception could construe perception more broadly as involving thoughts containing representational content. K-standards requiring activities directed at perception could then in a similar way resemble the platonic good if the latter's activities also involve representational content or even imagination. Such a position about the platonic good would most naturally fit with a view that it is an exemplar, and a mind. Similarly, the platonic good being a mind would bolster the claim made before that $\mathrm{K}$-standards requiring activities directed at rational activity would resemble the platonic good. Whatever the case, I realize that in order to further develop the above answer to the ranking question much more could be said about this perceptual and rational activity of the platonic good.

Lastly, I wish to argue that the platonic good exists in all metaphysically possible worlds. ${ }^{10}$ If it did not exist in all such possible worlds, but only some of them, a certain implausibility arises.

\footnotetext{
${ }^{10}$ Following Stephanie Leary, let us call metaphysical possibilities the "logical possibilities that are compatible with the essences of all things." (Leary 2017: 100) For members of living kinds, I contend that their essence as member of the kind is expressed by what Thompson calls the kind's "representation of life" (Thompson 1995).
} 
There would be some other possible worlds in which the platonic good does not exist. Yet, given the truth of $\mathbf{G}$ (which I take to hold in all metaphysically possible worlds) an individual's goodness obtains partly in virtue of its K-standard's resemblance with the platonic good. But if the latter does not exist there, then there is nothing in that world that can be good or even bad. However, it is intuitively plausible that those things can be evaluated, that is, that they have some goodness/badness value. Adams actually considers an analogous range of scenarios in which his favoured candidate for the Good, God, does not exist, or turns out to have a nature making him an unsuitable candidate for the role. Adams suggests some responses to these scenarios on behalf of his view (46). These responses, which he calls the "less ambitious approach", make excellence out to be un-instantiated in some worlds, or make what it is to be excellent radically contingent upon that world. But as he rightly points out, such scenarios and his responses to them "may fail to satisfy, due to the strong intuitive support for the view that excellence is so tightly tied to what things are like [i.e. what is the case about them] that it should not be a contingent matter what it would be excellent to be like." (46-47) He then offers a more ambitious approach according to which God necessarily exists with his (traditionally accepted) nature, avoiding all the unsatisfying implications above.

Applying a similar move to my account of goodness, it seems to be more reasonable to contend that whatever the platonic good is, its existence is metaphysically necessary. Otherwise, in some possible worlds nothing there would be good or bad. Further, the nature of the platonic good must not be compromised, and so I argue that its nature is also necessary, the metaphysical necessity explained by positing an essence for the platonic good. If its nature were not metaphysically necessary, then its nature could be so elastic that in some metaphysically possible world the kind-based standards for the Ebola-like microbe could resemble the platonic good. That would be unacceptable. For all these reasons, it seems to me more tenable that the platonic good's existence (including its nature) is metaphysically necessary.

\section{$\underline{\text { Works Cited }}$}

Adams, Robert Merrihew. Finite and infinite goods: A framework for ethics. New York: Oxford University Press, 2002.

Chan, B. "An Ebola-like microbe and the limits of kind-based goodness." Philosophia (forthcoming): $1-21$.

Dancy, Jonathan. "Discussion on the importance of making things right." Ratio 17.2 (2004): 229-237. Fitzpatrick. "Robust Ethical Realism, Non-naturalism, and Normativity." Oxford Studies in Metaethics 3. 2008. 159-205.

Foot, Philippa. Natural goodness. Oxford: Oxford University Press, 2001.

Foot, Philippa "Rationality and Goodness" in Modern Moral Philosophy ed. Anthony O'Hear. Cambridge: CUP, 2004.

Kosman, L. The activity of being: An essay on Aristotle's ontology. Harvard University Press, 2013.

Leary, Stephanie. "Non-naturalism and normative necessities." Oxford Studies in Metaethics 12 (2017): 76-105.

Murphy, Mark C. God and moral law: On the theistic explanation of morality. Oxford University Press, 2011. 
Putnam, Hilary. Philosophical Papers: Mind, Language and Reality. Vol. 2. Cambridge University Press, 1975.

Thompson, M. "The Representation of Life", in Hursthouse, Rosalind, Gavin Lawrence, and Warren Quinn ed., Virtues and reasons: Philippa Foot and moral theory: essays in honour of Philippa Foot. Oxford: Clarendon Press, 1995. 247-296. 